\title{
La Donación inoficiosa en el Código Civil Nacional
}

\author{
por el Dr. JOSE LEON BARANDIARAN
}

El art. 1469 de nuestro Código Civil se refiere al caso de donación inoficiosa. En salvaguarda de los derechos corrrespondientes a los herederos necesarios, la ley impone la limitación a que se refiere dicho artículo. Hay, así, un paralelismo entre lo que se permite y lo que se prohihe al disponente cuando la disposición se realiza por testamento (legado) y cuando se hace por donación. En ambos supuestos el principio es idéntico: defender las porciones que correspondan a los herederos reservatarios.

Se comprende, por lo tanto, que en lo que hace a la querella inoficiosae donationis, ella puede ser interpuesta por las personas que sean hedrederos forzosos del donante. La disposición del art. 1469 del actual Código Nacional reproduce la del número 593 del Códjgo anterior, en cuanto a la indicación de que el exceso de la asignación graciosa por encima de lo que puede disponer libremente el donans, se considerará relativamente al momento en que aquélla se haya producido. Este mismo criterio es el que ha sido acogido en el Código del Brasil (art. 1176). Es un criterio que se aparta radicalmente del preferido por la gran mayoria de las legislaciones que, consagrando la misma causal de inoficiosidad de la donación, estabiecen que la computación respectiva, para apreciar si ha habido exceso (estimando el monto del patrimonio del donante, las porciones de los legitimarios y el monto de la donación), se hará a la muerte del donante. Ahora bien, dentro del sistemo establecido en nuestro Código, una cuestión difícil de decidir es la consistente sobre el momento en que cabe demandar en base a la inoficio-

* Ex-Ministro de Justicia. Ex-Rector de la Universidad Nacional Mayor de San Marcos y Decano de su Facultad de Derecho. - Presidente de la Sección Peruana de la Co. misión Internacional de Juristas y de la Sociedad Peruana de Legislación Comparada. Catedrático de las Facultades de Derecho de la Universidad de San Marcos y de la Universidad Católica del Perú. 
sidad de la donación. Según Bevilaqua ("Código Civil dos Estados Unidos do Brasil", t. IV; pág. 342), seguido en esto por Carvalho de Santos ("Código Civil brasilero interpretado"; t. XVI, pág. 402), pueden demandar la nulidad de la donación, en cuanto ella sea inoficiosa, los hercderos necesarios del donante desde el momento en que se produce la doración, sin esperar la muerte de dicho donante. De esta opinión disiente Jo Lima ("Curso de direito brasilero"; t. II; "Dos contratos"; pág. 505); expresando: "esta nulidad sólo puede ser pedida por los herederos necesarios que fueran perjudicados con la donación excesiva $y$, en nuestro entender, solamente después de la muerte del donante, porque como dice Joao Luis Alves, antes de la muerte del donante no están investidos de derecho aiguno y tienen apenas una expectativa de derecho. Otros maestros entienden, sin embargo. que la acción de nulidad puede ser propuesta también aún en vida del donante, más no parece que ásí se deba entender porque, por lo demás, las mismas razones que impiden que sea objeto de contrato la herencia de persona viva (art. 1039), permanecen para que se discuta la herencia de persona viva".

Con referencia a nuestro Código se plantea, asi, tambié:1, la duda, la divergencia antes anotada. Ya en concernencia al Código Nacional anterior, nuestro ilustre Pacheco ("Tratado de Derecho Civil"; t. 11I, pág. 240), decia: "no hay reducción posible durante la vida del donante; y así debe ser, pues. to que sólo el donante tendria derecho para intentar la acción en reducción, v no es presumible que lo haga, aunque no fuese sino por no aparecer censurando su propia conducta. En la ley peruana, que contiene, como hemos visto, diferentes preceptos sobre reducción, hay silencio absoluto sobre el modo como debe ejercerse la acción respectiva y sobre las personas a quienes compete, y semejante falta puede muy bien dar margen a que las reducciones sean completamente ilusorias. En efecto, la ley no concede la acción al donante, y ya hemos indicado la razón que hay para que no sea verosimil que él la intente. Los herederos sólo gozan de los derechos y acciones que tenia el de cujus y no figurando en ellos la de reducción, el donatario podrá con fundamento negarles la facultad de reclamar. En la ley francesa, si no se concede la acción al donante, se concede expresamente y de una manera especial a sus herederos legitimarios, y a ese respecto no cabe la más ligera duda".

En realidad, las razones que se exponen en favor del criterio de que sólo a la muerte del donante cabe interponer la respectiva acción de nulidad, nos parecen decisivas. Mas, esto no deja de traer algunas complicaciones. Dentro del criterio seguido por la mayoría de los Códigos, en el sentido de que la apreciación respectiva se haga a la muerte del causante, lo que decide, pues, es la cuantía del patrimonio del donante en el momente de su muerte Ese momento, en relación al patrimonio dejado por el causante y a las legitimas que vienen a corresponder a los herederos, es el propiamente determinante. Pero dentro del sistema adoptado por nuestro Código, resulta que hay que retrotraer la apreciación al momento de la donación (si adoptamos la toma de posición de que sólo a la muerte del donante pueda entablarse la 
nulidad por el exceso de lo donado), con los inconvenientes que ello naturalmente tiene. Los cambios - favorables-- al patrimonio, sobrevenidos des pués de la donación y antes de la muerte del donante, resultan dentro del sistema, sin ninguna influencia. Más acertada es la solución de que se tome en cuenta el patrimonio tal cual es en su importe, en el momento de la muerte del de cujus, considerando los aumentos, el enriquecimiento que se haya producido, pues es en ese momento que se determina quienes son los herederos y cuales deben ser sus porciones legitimas.

Cabe preguntarse acerca de hasta qué punto la acción de donación inoficiosa es intentable, frente a la prescripción extintiva o usucapativa que puede favorecer al donatario (o a sus herederos) o a tercerns adquirientes. En primer lugar, hay que decir que la acción de prescripsión sólo puede comenzar a correr desde que se produjo la muerte del causante (dentro de la tesis de que sólo entonces es intentable la acción), por razón del principio de que actione non nate non prescribitur.

La acción extintiva prescribirá a los 15 años, por tratarse de una acción personel (art. 1168, inc. $2^{9}$ ).

En lo que hace a la prescripción usucapativa, se distingue según que se trate del donatario (o sus herederos) o de tercero adquiriente. Josserand dice: "está constantemente admitido que la acción en reducción prescribe por treinta años, y que este plazo no comienza a correr hasta el dia de la defunción del disponente; pero los terceros pueden, antes del cumplimiento de esta prescripción de derecho común usucapir por una posesión de diez o veinte años, de buena fe y fundada en justo titulo" ("Derecho Civil"; III; No 1723).

Es decir: que en favor del donatario sólo funciona la prescripción extraordinaria de dominio, porque no se le puede considerar con justo titulo; nero para el tercero adquiriente funciona la prescripción ordinaria de dominio, porque tiene justo título, siempre que a ello se agregue buena fe lo sea, que dicho adquiriente no conocia de la extralimitación en cuanto a la adquisición por su transferente, es decir, el defecto de inoficiosidad de la donación). De acuerdo a nuestro Código resulta:á, en consecuencia, que el donatario cumplidos los 30 años del art. 871, puede oponer en concernencia a inmuebles, la usucapión; y el tercero adquiriente, vencidos los diez años a que se refiere el mismo precepto (si tuvo buena fé, pues si nó, sólo podrá prevalecerse de la usucapión trentenaria).

Por inferencia de las reglas generales, los anteriores plazos de prescripción usucapativa se aplicarán tratándose de inmuebles, mientras que tratándose de mueb'es, tendrán que aplicarse los plazos de 4 y de 2 años, indicados en el art. 893.

Con el artículo 1469 de nuestro Código se relaciona el 1488, que dice que "si siendo dos o más las donaciones no cupieren todas en la parte disponible, se suprimirán o reducirán en cuanto al exceso las de fecha más reciente". Pero bien analizado el art. 1488, y si la anulación de la donación inoficiosa sólo se produce a la muerte del autor de aquélla (como creemos), 
resulta de una difícil aplicación adecuada dicho art. 1488, si nos atenemos a lo que ordena el art. 1469, sobre que "el exceso se regulará por el valor de los bienes que tuvo el donante al tiempo de la donación". No es del caso, pues, examinar conjuntamente las diversas donaciones sucesivas que haya podido hacer el donante, para determinar cuál o cuáles de ellas, y en que medida. se suprimen o reducen. Pues cada donación ha de ser examinada independientemente, sin relación a otra, desde que para cada donación la determinación sobre si es inoficiosa o nó se produce coetáneamente a su producción. Sólo ese momento es importante; y así se decide si esa donación de que se trate, en relación al momento de su producción, es compatible o nó con la libre disposición del autor. Por lo tanto, pues, si el dia de hoy Pedro hace una donación en favor de Pablo por la cantidad $x$, resultando que se han vulnerado las reservas hereditarias, (apreciada la cuestión a la muerte de Pedro), el heredero forzoso de Pedro, Juan, podrá solicitar !a reducción de tal doración hecha el dia de hoy. Pero si después del día de hoy el mismo Pedro, que en el interín ha mejorado de fortuna, hace una donación en favor de Santiago, y no resulta afectada la legítima del heredero Juan, éste a la muerte del de cujus Pedro, no podrá solicitar la reducción que favoreciese a Santiago. Es que -repetimos-a tenor de la última parţ del art. 1469 cada donación tiene que ser examinada independientemente, porque ha de serlo en relación al momento en que ella se ha producido.

Una disposición como la del 1488 es axplicable en los rọmenes legales que establecen que las donaciones, cuando cllas son susceptibles de ser calificadas de inoficiosas, serán consideradas - todas y cada una- a la muerte del donante y con relación al valor del patrimonio del causante en el momento de su muerte. Es el régimen generalmente seguido. De él se aparta el Códıgo brasilero (art. 1176), el anterior Código peruano (art. 593) y el actua) Código (art. 1488). Pero un precepto como el citado i488 no concuerda debidamente con el régimen que estima el exceso en que puede incurrirse en relación al momento en que se realiza la donación. Es, sin duda. por ello que dicho Código brasilero no contiene un precepto como el 1488 de nuestro Código, que en relación al 1469 (1176 del brasilero) delata una grave incongruencia. El Código Civil patrio de 1852 tampoco acusaba el defecto de incluir un precepto como el 1488 del actual Código.

Examinado, asi, el art. 1488 en depencencia necesaria con el 1469, no cabe preguntarse, como ocurre en cuanto a otras legislaciones, sobre si primero ha de procederse a la reducción de los legados y sólo después a la de las donaciones. Por otra parte, y siempre en relación con los efectos del art. 1469 , en cuanto a su última parte, que indica que el exceso se regulará pot el valor de los bienes del donante al tiempo de la donación, se pulede llegat a consecuencias absurdas, de entender el precepto literalmente. El donante podrá hacer una primera donación sin excederse del limite de disposición libre. Enseguida, inmediatamente, podrá hacer una segunda donación, sin tampoco excederse. $Y$ después una tercera $y$, así, sucesivamente. Ninguna de tales donaciones sería inoficiosa, pues cada una de ellas, en cuanto ei 
cómputo respectivo se efectuaría conforme a lo indicado en el art. 1649, no aparecería afectando la reserva hereditaria. Pero en el hecho resultará que tal reserva puede quedar reducida a casi nada. Pedro, que tiere abuelo, no puede disponer sino de la mitad de su patrimonio, por donación (art. 1469 y 701). Su patrimonio vale hoy como 80 . Hoy hace una donación en favor de Pabilo por 40 , y ella es válida. Mañana hace una donación en favor de Juan ( $y$ aún podria hacerlo en favor de Pablo) por 20 , y también esta segunda donación es válida. Pasado mañana hace una donación en favor de Santiago por 10; y también esta tercera denación es válida. En cada uno de los casos no se ha excedido el donans de lo permitido para el acto de liberalidad. Pero, en el hecho, ha resultadós vulnerada la porción que como legitima correspondia al abuelo de Pedro (ha quedado reducida a 10). En realidad, por eso, el sistema más conveniente es el generalmente seguido por las legislaciones, en cuanto a que la apreciación ha de hacerse al tiempo de la muerte del donante. $Y$ entonces si cabe que funcione perfectamente lo ordenado en el art. 1488. Para evitar que sobrevengan las consecuencias desconcertantes que puedan derivar de la aplicación literal del art. 1469 , no queda otro remedio que interpretarlo jure condendo, en el sentido de que cuando se efectúa una donación, deba tenerse en cuenta la donación o donaciones anteriores, para determinar si por éstas últimas ya se ha llegado o nó al límite de la cuota de disposición libre. Asi, en el ejemplo anteriormente utilizado, la segunda donación a favci de Juan sería nula, porque ya en la primera donación se llegó al límite. Ello siempre que no haya mejorado, aumentado el patrimonio del donante, porque entonces podria disponer válidamente, pero solo en la parte proporcional respectiva a ese aumento. Asi si la primera donación fue por 40 en favor de Pablo sobre un patrimonio de 80 , y después Pedro enriquece su patrimonio en 10, podrá donar 5, y nada más que 5, a Juan. Si la primera donación fue inferior a la cuota disponible (Pedro sobre su patrimonio de 80 donó a Pablo 30), queda un remanente disponible libremente, de 10 , que podria donar a Juan válidamente. $\mathrm{Si}$, por otra parte, en el mismo caso, de remanente, ha aumentado el patrimonio de Pedro (supc" amos en 10 más), entonces, podrá disponer de 15 en favor de Juan: 10 por el remanente de la primera donación y 5 por la parte proporcional al aumento sobrevenido.

Si se examina cuidadosamente el asunto ahora tratado, con otros atinentes a la donación, dentro de nuestro Código Civil, se puede reparar en que la institución aparece estructurada de manera tal que se puede decir que lo ha sido un tanto perfunctoriamente. Con referencia a csta institución, como otras de nuestro Código, se puede observar que, sin negar los méritos de éste, sobre todo en comparación con el Código de 1852, se requiere un trabajo de revisión del Código vigente, después de 25 años desde que fuera promuigado. 